\title{
İyi Sınıf Öğretmeni Özelliklerine Yönelik Öğrenci, Öğretmen ve Veli Görüşleri: Bir Temel Nitel Çalışma
}

\author{
Mutlu Uygur*, Sedat Kanadlı \\ Eğitim Fakültesi, Eğitim Programları ve Öğretim Bölümü, Mersin Üniversitesi, Mersin, Türkiye \\ ORCID: M. Uygur (0000-0002-7756-2576), S. Kanadlı (0000-0002-0905-8677)
}

\begin{abstract}
Özet
Bu çalışmada alan yazında nitelikli, yeterli sınıf öğretmeni, toplumsal bağlamda iyi sınıf öğretmeni olarak tanımlanan öğretmenlik alanına ilişkin "iyi” olma özelliğinde belirleyici olan görüşlerin incelenmesi amaçlanmıștır. Bu amaç doğrultusunda derinlemesine bilgi edinmek amacıyla araștırmada, Temel Nitel Çalıșma Modeli kullanılmıștır. Araștırmanın çalışma grubunu, Mersin ilinde 4. sınıflarda öğrenim gören 31 öğrenci, bu okullarda görev yapan 16 sınıf öğretmeni ve farklı sınıflarda öğrencileri bulunan 28 öğrenci velisi olușturmaktadır. Araștırmada, iyi sınıf öğretmeni özelliklerini belirlemek amacıyla, elverișli örneklem yöntemiyle seçilmiș öğrenci, sınıf öğretmeni ve velilerin "Sizce iyi bir sınıf öğretmeni hangi özelliklere sahip olmalıdır?” sorusunu cevaplandırmaları sağlanmıştır. Çalışmada, öğrenci, öğretmen ve velilerin tamamının yüksek katılım gösterdiği iyi sınıf öğretmenine ilişkin ortak görüşün "öğrenciyi seven" ifadesi olduğu görülmüștür. Diğer en yüksek katılım gösterilen ifade ise özellikle öğretmen ve velilerin üzerinde durduğu "donanımlı (bilgili)" ifadesi olmuştur. Sonuç olarak, öğrenciyle empati kurabilen, onlarla arkadaş olan, dersi aktif ve eğlenceli hale getiren ve öğrenmeyi artırabilmek için gerekli donanım ve bilgiye sahip öğretmen özelliklerinin, iyi sınıf öğretmeni algısında önemli oranda belirleyici olduğu sonucuna ulaşılmıștır.
\end{abstract}

Anahtar kelimeler: Temel nitel çalışma; iyi sınıf öğretmeni; öğrenci, öğretmen ve veli görüşleri

\section{Opinions of Students, Teachers and Parents Regarding Good Primary School Teacher Characteristics: A Basic Qualitative Study}

\begin{abstract}
In this study, it is aimed to examine the opinions that are determinant about being "good" in the field of teaching defined as qualified, sufficient primary school teacher in the literature and good primary school teacher in the social context. For this purpose, the basic qualitative study model was used in the research in order to obtain in-depth information. The study group of the research consists of 31 students studying in 4th grade in Mersin, 16 classroom teachers working in these schools and 28 parents of students with students in different classes. In the research, in order to determine the characteristics of a good primary school teacher, the students, primary school teachers and parents who were chosen with the appropriate sampling method asked "What characteristics do you think a good primary school teacher should have?" They were provided to answer the question. In the study, it was seen that the common view about the good primary school teacher, in which all of the students, teachers and parents were highly attended, was the expression "loving the student". The other most attended statement was the phrase "equipped (knowledgeable)", especially emphasized by teachers and parents. As a result, it was concluded that the characteristics of the teacher who can empathize with the student, make friends with them, make the lesson active and entertaining, and have the necessary equipment and knowledge to increase learning are significantly determining in the perception of good primary school teachers.
\end{abstract}

Key words: Basic qualitative study; good primary school teacher; opinions of students; teachers and parents

\section{Giriş̧}

Eğitimin temel unsurlarından biri öğretmendir. Öğretmenin hem toplumsal hem de okul içinde önemli rolleri

*Yazışma Adresi / Address for Correspondence:

M. Uygur Email: mutluygur@gmail.com

Geliş Tarihi / Received Date: 16.03 .2020

Kabul Tarihi / Accepted Date: 10.04 .2020

Doi: 10.26701/uad.704896 vardır. Özellikle öğrencinin başarısında, öğretmenin yeri ve önemi yadsınamaz. Bu bağlamda, öğretmenlik mesleği profesyonellik gerektiren özel bir meslektir (Yıldırım, Ünal ve Çelik, 2011). Bu bağlamda, eğitim ve öğretim faaliyetlerinin kilit konumunda öğretmen bulunmaktadır. Beydoğan (2001)' a göre hiçbir sistem, sistemi işleten bireyin niteliğinin ötesine geçemez. Öğretme-öğrenme sürecinde öğretmenin yerini hiçbir ögenin doldurması mümkün değildir. Çünkü öğretmen, çeşitli öğretim yöntem ve tekniklerinden yararlanarak öğrenme ortamları- 
nı düzenleyen, öğrenmeyi kılavuzlayan, öğretim ișinin nicelik ve niteliğini planlayan, uygulamayı yürüten ve öğrencileri değerlendiren kişidir (Fidan ve Erden, 1994; Beydoğan, 2001). Eğitimin geliştirilmesinde öğretmenin rolü günümüzde herkes tarafından bilinmektedir. Bir toplumun kalkınması için öncelikle yetişmiş insan gücüne ihtiyaç vardır. Yetişmiş insan gücünü sağlayacak kurumlar ise okullardır. Bir okulun iyi olabilmesi de büyük ölçüde öğretmenler tarafından verilen eğitimin kalitesine bağlıdır (Seferoğlu, 2001). Alanyazında birçok çalışmada eğitimin sonuçlarını ve çıktılarını etkileyen en önemli değişkenin öğretmenlerin yeterlikleri ve nitelikleri olduğu ortaya konulmuştur (Darling-Hammond, 2000; Dodeen, vd., 2012; Hanushek ve Rivkin, 2006; Lewis, vd., 1999). Bu doğrultuda, eğitim alanında tasarlanan hedeflere ulaşabilmenin, bu sürece yön veren öğretmenlerin nitelik ve yeterlikleriyle yakından ilişkili olduğu görülmektedir. Öğretmen yeterlikleri kavramı, öğretmenlerin “öğretmenlik mesleğini etkili ve verimli bir biçimde yerine getirebilmek için sahip olmaları gereken bilgi, beceri ve tutumlar" olarak tanımlanmaktadır (MEB, 2006).

Eğitim tarihimize baktığımızda öğretmenlik mesleğini yürütecek olanların sahip olması gereken özelliklerin ve yeterliklerin, Milli Eğitim Bakanlığı (MEB) ve akademik çevrelerin yaptığı çalışmalar, tanımlamalar ve sınıflamalar çerçevesinde süreç içerisinde farklılaşmalar gösterdiğini görmekteyiz (Küçükahmet, 1999; Özdemir ve Yalın, 1999; Alkan, 2000; Çakır, Erkuş ve Kılıç, 2000; Uygur ve Çakır, 2015). Şeker, Deniz ve Görgen'e (2005) göre, bu çalışmalarda yeterlikle ilgili farklı tanımlamalar yapılmasına rağmen, öğretmenlerin konu yeterlikleri, kişilik özellikleri, öğrenmeyi öğretme becerileri, sınıf yönetimi becerileri, planlama, değerlendirme becerileri, teknolojiyi kullanma, iletişim ve rehberlik becerileri gibi yeterliklere sahip olmaları, öğretmenlerin öğretme-öğrenme sürecinde nitelikli olmalarını sağlayan temel değişkenlerdir.

MEB (2002; 2006; 2007; 2008; 2017) tarafından farklı yıllarda öğretmen yeterliklerinin geliştirilmesine yönelik çalışmalar yürütülmüştür. Bu çalışmalarda öğretmen yeterliliklerinin geliştirilmesi sürecinde iyi öğretmenin sahip olması gereken özellikler belirlenmiş ve sonra bu özellikler gruplanarak yeterlik alanları oluşturulmuştur. Daha sonra öğrenme alanları dikkate alınarak ve bilimsel bilgilerden yararlanılarak geliștirilen yeterlilik alanları ışığında yeterlik bildirimlerine ve yeterliklere sahip olan öğretmenin göstermesi gereken davranışları örnekleyen göstergelere ilişkin üniversitelerde ve alanda çalışan öğretmenlerin görüşleri dikkate alınarak yeterliklere son hali verilmiştir (Özyürek, 2008). MEB'in (2017:8) hazırladığı öğretmenlik mesleği genel yeterlikleri kılavuzuna göre, güncellenen öğretmenlik Mesleği Genel Yeterlikleri; "Mesleki Bilgi (Alan Bilgisi, Alan Eğitimi Bilgisi, Mevzuat Bilgisi)", "Mesleki Beceri (Eğitim Öğretimi Planlama, Öğrenme Ortamları Oluşturma, Öğretme ve Öğrenme Sürecini Yönetme, Ölçme ve Değerlendirme)”, “Tutum ve Değerler (Millî-Manevi ve Evrensel Değerler, Öğrenciye
Yaklaşım, İletişim ve İș Birliği, Kişisel ve Mesleki Gelişim)" olmak üzere birbiriyle ilişkili ve birbirini tamamlayan 3 yeterlik alanı ile bunlar altında yer alan 11 yeterlikten oluşmaktadır. Öğretmenlerin sahip olması gereken nitelikler ve yeterlikler her öğretim düzeyinde, her alanda ya da disiplinde çok önemlidir. Öğretmenlik alanlarının tamamında öğretmenlerin belirlenen yeterliklere sahip olmaları ve eğitimin bütün basamaklarında, tüm alan ya da branşlarda öğretmenlerin nitelikli öğretme-öğrenme süreçleri düzenlemeleri beklenmektedir.

Öğretmenlik alanları içerisinde sınıf öğretmenliği alanı öğretmenlerden beklentiler, beklenen yeterlikler ve nitelikler olarak diğer alan öğretmenliklerinden farklılık göstermektedir. Çelik, Yorulmaz ve Çokçalışkan'a (2019) göre, sınıf öğretmenleri, eğitim sürecinin başlangıcına rehberlik ederek bireyin temel yaşamsal bilgi ve becerilerini kazanmasında kritik rol oynayan önemli bir etkendir. Dolayısıyla ideal sınıf öğretmeni olarak nitelendirilebilecek öğretmenin, genel mesleki yeterliklere sahip olması önem arz etmektedir. Sınıf öğretmenlerinden beklenen yeterlikler ve nitelikler şu ana kadar MEB'in yeterlikleri belirleme ve tanımlamaya yönelik çalışmalarıyla ortaya konulmuştur. MEB'in ortaya koyduğu uluslararası kalite standartları ve normlarından oluşan bu yeterlikler, akademisyen, eğitim uzmanları ve öğretmenlerin görüşleri doğrultusunda belirlenmiştir (Taşkaya, 2012). Sınıf öğretmenlerinden toplumun beklentileri ve öğrencilerin beklentileri ortaöğretim ve yükseköğretim alanından farklı olarak daha çok pedagojik yeterliklere doğru bir eğilim göstermektedir. Bu doğrultuda sınıf öğretmenlerinden beklenen niteliklere ve yeterliklere yönelik öğretmen, öğrenci ve veli görüşlerinin belirlenmesi önemli görülmektedir. Alan yazın incelendiğinde sınıf öğretmenlerinden beklenen niteliklere ve yeterliklere yönelik öğretmen, öğrenci ve veli görüşlerinin çalışma konusu yapıldığı bir çalışmaya rastlanılmamıştır. Toplumda nitelikli sınıf öğretmeni kavramının "iyi sınıf öğretmeni” kavramıyla tanımlandığı görülmektedir. Bütün velilerin çocuklarını ilkokula gönderirken uygun taleplerini karşılayabilecek, genel bir ifadeyle "iyi sınıf öğretmeni" arayışına girdikleri bilinmektedir. Bu yadırganamayacak bir durumdur. Bu noktada bu çalışmada, toplumda sıklıkla vurgulanan "iyi sınıf öğretmeni” kavramının öğrenci, veli ve öğretmen gözüyle her bir paydaşın görüşleri alınarak araştırılması ve iyi sınıf öğretmeni özelliklerine yönelik paydaşların görüşlerine çoklu bir pencereden bakılması amaçlanmıştır. $\mathrm{Bu}$ çalışmada ayrıca ulusal ve uluslararası alan yazında böyle bir çalışmaya rastlanmamış olması açısından da alana katkı sağlanması amaçlanmıştır.

$\mathrm{Bu}$ amaç doğrultusunda çalışmanın ana problem cümlesi ve alt problemler şu şekilde belirlenmiştir:

Ana problem cümlesi:

İyi sınıf öğretmeni özelliklerine yönelik görüşler nelerdir? Alt problemler: 
1. İyi sınıf öğretmeni özelliklerine yönelik öğrenci görüşleri nelerdir?

2. İyi sınıf öğretmeni özelliklerine yönelik öğretmen görüşleri nelerdir?

3. İyi sınıf öğretmeni özelliklerine yönelik veli görüşleri nelerdir?

\section{YÖNTEM}

Araştırma, temel nitel çalışma modelinde yapılandırılmıştır. Temel bir nitel çalışmada, araştırmacı insanların deneyimlerini nasıl anlamlandırdığı ve yorumladığıyla ilgilenmektedir (Merriam, 2002). Meriam'e (2013:22) göre temel nitel araştırmaları yürüten araştırmacılar, insanların yaşamlarını nasıl yorumladığıyla, dünyalarını nasıl inşa ettikleriyle ve deneyimlerine ne anlam kattıklarıyla ilgilenirler. Temel nitel çalışmalar, bir fenomenin ayrıntılı hesaplarını, fenomenin yorumlarını (kavramsal kategoriler ve önceki araştırmalar arasındaki ilişkiler) ve yeni anlayıșlarını ortaya koyar (Merriam, 1998). Nitel durum çalışmalarının en önemli özelliği bir durumun derinlik odaklı araștırılarak o duruma ilișkin sonuçların ortaya koyulmasıdır (Yıldırım ve Şimşek, 2018). Bu çalışmada bu nedenle, iyi sınıf öğretmeni özelliklerine yönelik derinlemesine ve çoklu bakış açısıyla görüşleri belirlemek ve bir yargıya varabilmek amacıyla temel nitel çalışma modeli kullanılmasına karar verilmiştir.

\section{1. Çalışma grubu}

Araştırmanın çalışma grubunu, Mersin ilinde 2 resmi devlet okulunda 4. sınıflarda öğrenim gören 31 öğrenci, bu okullarda görev yapan 16 adet sınıf öğretmeni ve farklı sınıflarda öğrencileri bulunan 28 öğrenci velisi oluşturmaktadır.

\subsection{Veri toplama araçları}

Araştırmada, iyi sınıf öğretmeni özelliklerini belirlemek amacıyla, elverişli örneklem yöntemiyle seçilmiş öğrenci, sınıf öğretmeni ve velilerin "Sizce iyi bir sınıf öğretmeni hangi özelliklere sahip olmalıdır?” sorusunu cevaplandırmaları sağlanmıștır. Tek maddelik araştırma sorusunu içeren formda ayrıca demografik bilgileri içeren bir kısımda yer almaktadır. Katılımcıların görüş, düşünce ve demografik bilgilerini formda yer alan uygun boşluklara doldurmaları istenmiştir.

\subsection{Verilerin analizi}

Araştırma sorusunu içeren formdan elde edilen veriler içerik analizine tabi tutulmuştur. İçerik analizi yöntemi sübjektif yorumlamaların bulunduğu metinlerin kodlama ve temalaştırma süreçlerinin sistematik sınıflamasını içermektedir (Hsieh \& Shannon, 2015). Verilerin analizinde NVIVO 10 istatistik programı kullanılmıştır. Araştırmadan elde edilen nitel bulgular, 2 araştırmacı tarafından analiz edilmiştir. Bulgular içerik analizi yöntemince kod ve temalara ayrılmış, elde edilen kodların frekans ve yüzdeleri sunulmuştur. Açık uçlu sorudan elde edilen bulguların kodlayıcı güvenirliği için Miles-Huberman (1994) kodlayıcı güvenirliği formülü kullanılmıștır. Miles-Huberman kodlayıcı güvenirliği ile elde edilen güvenirlik düzeyleri aşağıda Tablo 1' de verilmiștir.

Tablo 1. Miles-Huberman Güvenirlik Değerleri

\begin{tabular}{|c|c|}
\hline Görüssler & Güvenirlik Değeri \\
\hline Öğrenci & 0.78 \\
\hline Öğretmen & 0.90 \\
\hline Veli & 086 \\
\hline
\end{tabular}

\section{BULGULAR VE YORUM}

Çalışmada öğrenci, öğretmen ve velilerin iyi sınıf öğretmeni özelliklerine ilişkin görüşleri ayrı ayrı kodlanmış ve ifadeler benzerliklerine göre kategorize edilmiștir. Elde edilen bulgulara göre, iyi sınıf öğretmeni özelliklerine yönelik görüşlere ilişkin elde edilen tanımlar (kodlar) ve tanımların yer aldığı kategorilere ilişkin oranlar, aşağıda Tablo 2, 3 ve 4'te verilmiştir.

Tablo 2. İyi Öğretmen Özelliklerine Yönelik Öğrenci Görüşleri

\begin{tabular}{|c|c|c|c|}
\hline Kategori & Tanım (Kodlar) & (N) & Yüzde (\%) \\
\hline $\begin{array}{c}\text { Öğrenciye } \\
\text { İyi Davranan }\end{array}$ & $\begin{array}{l}\text { İyi bir sını öğretmeninin; öğrencileri seven } \\
\text { (kötü davranmayan, bağırmayan, kızmayan, } \\
\text { iyi yürekli) onlara iyi, dostça, samimi davra- } \\
\text { nan, öğrencileri eğlendiren, güldüren güzel } \\
\text { zaman geçirmelerini sağlayan, güler yüzlü } \\
\text { ve bütün öğrencilere eşit yaklaşan (adil) } \\
\text { özelliklere sahip olduğunu belirten ifadeler. }\end{array}$ & 21 & 43.75 \\
\hline İyi Öğreten & $\begin{array}{l}\text { İyi bir sınıf öğretmeninin; konuları kolay öğ- } \\
\text { renmelerini sağlayan, anlaşılamayan yerleri } \\
\text { açıklayan, kendi seviyelerine uygun ders yü- } \\
\text { rüten ve dersi eğlenceli hale getiren öğret- } \\
\text { men özelliklerine sahip olduğunu belirten } \\
\text { ifadeler. }\end{array}$ & 13 & 27.08 \\
\hline $\begin{array}{c}\text { Özel } \\
\text { yetenek } \\
\text { derslerini } \\
\text { önemseyen }\end{array}$ & $\begin{array}{l}\text { İyi bir sınıf öğretmeninin; beden eğitimi, } \\
\text { görsel sanatlar, müzik dersleri gibi öğren- } \\
\text { cilerin Türkçe, matematik ve fen dersleri } \\
\text { dışındaki özel yetenek gelişimlerini des- } \\
\text { tekleyen dersleri de önemseyen öğretmen } \\
\text { özelliklerine sahip olduğunu belirten ifa- } \\
\text { deler. }\end{array}$ & 12 & 25 \\
\hline Diğer & $\begin{array}{l}\text { İyi bir sınıf öğretmeninin; öğrencilerin } \\
\text { olumlu davranışlarını ödüllendiren, kılık } \\
\text { kıyafetlerini görünüşünü, saçlarını vs. sorun } \\
\text { etmeyen özelliklere sahip olduğunu belir- } \\
\text { ten ifadeler. }\end{array}$ & 2 & 4.1 \\
\hline
\end{tabular}

Tablo 2'de yer alan bulgulara göre öğrenciler, iyi sınıf öğretmeni özellikleri olarak, "öğrenciye iyi davranan" (\% 43.75), "iyi öğretici" (\% 27.08), "yetenek derslerini önemseyen" (\% 25), diğer (\% 4.1), kategorileri içinde tanımlanan görüşleri belirtmişlerdir.

Tablo 3. Iyi Öğretmen Özelliklerine Yönelik Öğretmen Görüşleri

\begin{tabular}{|c|l|c|c|}
\hline Kategori & \multicolumn{1}{|c|}{ Tanım (Kodlar) } & (N) Yüzde (\%) \\
\hline Donanımlı & $\begin{array}{l}\text { lyi bir sınıf öğretmeninin yenilikçi yaklaşım- } \\
\text { lar gösteren, alanına hâkim, planlı programlı, } \\
\text { kendini geliştiren, Bilgi İletişim Teknolojilerini } \\
\text { kullanan, farklı kaynaklardan yararlanan, öğ- } \\
\text { renci ve veli ile iletişim becerileri güçlü olan } \\
\text { öğretmen özelliklerine sahip olduğunu belir- } \\
\text { ten ifadeler. }\end{array}$ & 23 & 28.04 \\
\hline $\begin{array}{c}\text { Öğrenciyi } \\
\text { Seven }\end{array}$ & $\begin{array}{l}\text { lyi bir sınıf öğretmeninin öğrenciyi seven, } \\
\text { güler yüzlü, sevecen, sabırlı, adil, fedakâr öğ- } \\
\text { retmen özelliklerine sahip olduğunu belirten } \\
\text { ifadeler. }\end{array}$ & 19 & 23.17 \\
\hline
\end{tabular}




\begin{tabular}{|c|c|c|c|}
\hline Kategori & Tanım (Kodlar) & (N) & Yüzde (\%) \\
\hline $\begin{array}{l}\text { Mesleğini } \\
\text { Seven }\end{array}$ & $\begin{array}{l}\text { İyi bir sınıf öğretmeninin mesleğini seven, } \\
\text { çevresine örnek davranışlar gösteren, rol mo- } \\
\text { del olan, örnek öğrenciler yetiştiren, eğitime } \\
\text { önem veren öğretmen özelliklerine sahip ol- } \\
\text { duğunu belirten ifadeler. }\end{array}$ & 18 & 21.95 \\
\hline $\begin{array}{c}\text { Öğrenci } \\
\text { Merkezli } \\
\text { Olan }\end{array}$ & $\begin{array}{l}\text { İyi bir sınıf öğretmeninin öğrenci merkezli } \\
\text { yöntemler kullanan, öğrenci yaratıcılıklarını } \\
\text { ve farklılıklarını önemseyen ve öğrencilerin } \\
\text { kişisel gelişimlerini destekleyen, dersi eğ- } \\
\text { lenceli hale getiren, öğrencileri motive eden, } \\
\text { sosyal faaliyetleri ve beden eğitimi, resim, } \\
\text { müzik dersleri gibi özel yetenek derslerini de } \\
\text { önemseyen öğretmen özelliklerine sahip ol- } \\
\text { duğunu belirten ifadeler. }\end{array}$ & 17 & 20.73 \\
\hline Diğer & $\begin{array}{l}\text { İyi bir sınıf öğretmeninin kılık, kıyafet, saç gibi } \\
\text { dış görünüs̆ özelliklerine önem veren öğret- } \\
\text { men özelliklerine sahip olduğunu belirten } \\
\text { ifadeler. }\end{array}$ & 5 & 6.09 \\
\hline
\end{tabular}

Tablo 3'te yer alan bulgulara göre öğretmenler, iyi sınıf öğretmeni özellikleri olarak, "donanımlı" (\% 28.04), “öğrenciyi seven” (\% 23.17), "mesleğini seven” (\% 21.95) “öğrenci merkezli olan” (\% 20.73) ve diğer (\% 6.09), kategorileri içinde tanımlanan görüşleri belirtmişlerdir.

Tablo 4. İyi Öğretmen Özelliklerine Yönelik Veli Görüşleri

\begin{tabular}{|c|c|c|c|}
\hline Kategori & Tanım (Kodlar) & $(\mathrm{N})$ & Yüzde (\%) \\
\hline $\begin{array}{l}\text { Öğrenciyi } \\
\text { Seven }\end{array}$ & $\begin{array}{l}\text { İyi bir sınıf öğretmeninin öğrencilere karşı } \\
\text { iyi davranan, şiddet kullanmayan, sabırlı, } \\
\text { güler yüzlü, iyi kalpli, onları seven, öğrenci- } \\
\text { leriyle birebir ilgilenen, hoşgörülü, öğrenci- } \\
\text { ler arası ayrım yapmayan öğretmen özellik- } \\
\text { lerine sahip olduğunu belirten ifadeler. }\end{array}$ & 23 & 43.39 \\
\hline Donanımlı & $\begin{array}{l}\text { İyi bir sını öğretmeninin çok yönlü, tekno- } \\
\text { lojiyi, yeni yöntem ve teknikleri derslerinde } \\
\text { kullanabilen, farklı kaynaklardan yararla- } \\
\text { nan, öğrenci ve veli ile iletişimi güçlü olan, } \\
\text { planlı programlı öğretmen özelliklerine sa- } \\
\text { hip olduğunu belirten ifadeler. }\end{array}$ & 16 & 30.18 \\
\hline Disiplinli & $\begin{array}{l}\text { İyi bir sınıf öğretmeninin sınıf içinde düzeni } \\
\text { ve otoriteyi sağlayan, disiplinli bir sınıf orta- } \\
\text { mı oluşturan öğretmen özelliklerine sahip } \\
\text { olduğunu belirten ifadeler. }\end{array}$ & 9 & 16.98 \\
\hline İşini Seven & $\begin{array}{l}\text { İyi bir sınıf öğretmeninin mesleğini seven, } \\
\text { işini severek yapan öğretmen özelliklerine } \\
\text { sahip olduğunu belirten ifadeler. }\end{array}$ & 3 & 5.66 \\
\hline $\begin{array}{l}\text { Görünüşüne } \\
\text { Önem Veren }\end{array}$ & $\begin{array}{l}\text { İyi bir sınıf öğretmeninin kılık, kıyafet ve saç } \\
\text { gibi kendi kişisel bakımına ve görüntüsüne } \\
\text { dikkat eden öğretmen özelliklerine sahip } \\
\text { olduğunu belirten ifadeler. }\end{array}$ & 2 & 3.77 \\
\hline
\end{tabular}

Tablo 4'te yer alan bulgulara göre veliler, iyi sınıf öğretmeni özellikleri olarak, "öğrenciyi seven” (\% 43.39), "donanımlı" (\% 30.18), "disiplinli” (\% 16.98), "işini seven (\% 5.66) ve "görünüşüne önem veren” (\% 3.77) kategorileri içinde tanımlanan görüşleri belirtmişlerdir.

\section{TARTIŞMA VE SONUÇ}

Bütün öğretmenlik alanlarında olduğu gibi ilköğretimin birinci kademesinde eğitim-öğretim hizmetlerini yürüten sınıf öğretmenlerinden de beklenen bazı yeterlikler ve özellikler vardır. Bunları, öğrencinin beklediği özellikler, öğretmenlere göre ve velilere göre iyi öğretmen özellikleri olarak 3 farklı bakış açısıyla incelemek mümkündür. Özellikle sınıf öğretmenlerinden velilerin beklentisi ve talepleri çocukla empati kurma, okulu sevdirme, anne-baba olabilme, iyi eğitim sunabilme, model olabilme gibi çeşitli pedagojik taleplerle diğer alan öğretmenliklerinden farklılaşmakta ve çeşitlenmektedir. Alan yazında sınıf öğretmenlerinden beklenen nitelikler, mesleki bilgi (olgular, ilkeler, süreçler ve genel kavramlar bilgisi), mesleki beceri (bilişsel ve uygulamaya dayalı beceriler bilgisi) ve mesleki nitelikler (kişisel özellikler: vizyon, değerler, tutumlar sorumluluklar, vb.) boyutlarında ele alınmaktadır (Bubb ve Mortimore, 2013; Darling-Hammond ve Baratz-Snowden, 2007; Peacock ve Gates 2000; Thompson ve Smith, 2005). Bu çalışmada ulaşılan sonuçlar alan yazındaki bu bulguları destekler niteliktedir. Bu çalışmada ulaşılan sonuçlara göre, iyi sınıf öğretmenlerinden beklenen özellikler mesleki bilgi boyutunda; "donanımlı", mesleki beceri boyutunda; "iyi öğreten, öğrenci merkezli olan" ve mesleki nitelik boyutunda; "öğrenciye iyi davranan, görünüşüne önem veren, öğrenciyi seven, mesleğini seven, disiplinli, işini seven" ifadelerini içeren kategorilerden oluşmaktadır. Buldu (2014), bilim ve toplumda meydana gelen değişimleri takip edip bunları sınıflarında yansıtabilme becerileri gösterebilen, sorumluluğunu üstlendiği öğrencilerine model olabilen, çağdaş öğretim yöntem ve teknikleri ve araçlarını etkili bir şekilde kullanabilen öğretmenlerin eğitimin kalitesini yükselttiğini vurgulamıştır. Bu çalışmada öğretmen ve veli görüşlerine göre iyi sınıf öğretmeni özelliklerine yönelik ulaşılan sonuçlarda "donanımlı, iyi öğreten, öğrenci merkezli ders yürüten" ifadeleri bu görüşü destekler niteliktedir. (Taşkaya, 2012), sınıf öğretmeni adaylarının görüşlerini incelediği çalışmasında nitelikli bir öğretmende bulunması gereken mesleki özelliklerin başında öğretmenin adil olması ve öğretmenlik alan bilgisinin yeterli olması gerektiği sonucuna ulaşmıştır. Bu çalışmada, iyi sınıf öğretmeninin öğrenciler arası ayrım yapmayan ve donanımlı olmaları yönünde ulaşılan öğretmen görüşleri bu sonuçlarla paralellik göstermektedir.

Çalışmada ulaşılan sonuçlar incelendiğinde öğrenci, öğretmen ve velilerin üçünün de yüksek katılım gösterdiği iyi sınıf öğretmenine ilişkin ortak görüşün "öğrenciyi seven” ifadesi olduğu görülmektedir. Diğer en yüksek katılım gösterilen ifade ise özellikle öğretmen ve velilerin üzerinde durduğu "donanım" ifadesi olmuştur. Sonuç olarak iyi sınıf öğretmeni algısında, öğrenciyle empati kurabilen, onları seven, kendini sevdiren öğretmen özelliklerinin yanında dersi aktif ve eğlenceli hale getirip öğrenmeyi artırabilmek için gerekli donanıma sahip öğretmen özelliklerinin önemli oranda belirleyici olduğu sonucuna ulaşılmıştır.

\section{5. ÖNERILER}

- Sınıf öğretmenliği alanına ilişkin yeterlikler ve nitelikleri belirlemede, uluslararası normlar, akademisyen, öğrenci, veli ve öğretmen görüşlerinin ve beklentilerinin dikkate alındığı çok yönlü bakış açısını içeren bir model geliştirilebilir.

- İyi ya da nitelikli sınıf öğretmeni özelliklerine yönelik 
görüşlere göre sınıf öğretmenliği lisans programları güncellenebilir.

- Sınıf öğretmenliği çalışma alanı ve koşullarını düzenlemeye ilişkin bu görüş ve beklentiler yol gösterici olabilir.

- İyi sınıf öğretmeni özelliklerini belirlemek için farklı ölçme araçları kullanılabilir.

- İleride yapılacak çalışmaların daha fazla katılımcıyla yapılması önerilmektedir.

- Durumun daha net ortaya konulması amaciyla İleride yapılacak çalışmaların karma desende yapılandırması önerilmektedir.

\section{KAYNAKÇA}

Alkan, C. (2000). Meslek ve öğretmenlik mesleği. Sönmez, V. (Ed.), Öğretmenlik mesleğine giriş içinde (ss. 191-230). Ankara: Anı Yayıncılık.

Beydoğan, H. Ö. (2001). Öğretimde planlama ve değerlendirme. Erzurum: Eser Ofset.

Bubb, S., \& Mortimore, P. (2013). The Effective Induction of Newly Qualified Primary Teachers: An Induction Tutor's Handbook. New York: Routledge.

Buldu, M. (2014). Öğretmen yeterlik düzeyi değerlendirmesi ve mesleki gelişim eğitimleri planlanması üzerine bir öneri. Milli Eğitim Dergisi, 44(204), 114-134.

Çakır, Ö., Erkuş, A., ve Kılıç, F. (2000). Mersin Üniversitesi 19992000 yılı öğretmenlik meslek bilgisi programının (ÖMBP) çeşitli değişkenler açısından değerlendirilmesi, Mersin Üniversitesi Araştırma Fonu Saymanlığı EF (ÖÇ) 2000-1 nolu Araştırma Projesi.

Çelik, Ö., Yorulmaz, A., \& Çokçalışkan, H. (2019). Öğretmen genel yeterlikleri açısından sınıf öğretmenleri ve öğretmen adaylarının kendilerini değerlendirmeleri. Eskişehir Osmangazi Üniversitesi Sosyal Bilimler Dergisi, 20 (Özel Sayı), 203-215. https:// doi.org/10.17494/ogusbd.548342

Darling-Hammond, L. (2000). Teacher quality and student achievement. Education Policy Analysis Archives, 8 (1), 1-44. https://doi.org/10.14507/epaa.v8n1.2000

Darling-Hammond, L., \& Baratz-Snowden, J. (2007). A good teacher in every classroom: Preparing the highly qualified teachers our children deserve. Educational Horizons, 85(2), 111 132.

Dodeen, H., Abdelfattah, F., Shumrani, S., \& Hilal, M. A. (2012). The effects of teachers' qualifications, practices, and perceptions on student achievement in TIMSS mathematics: A comparison of two countries. International Journal of Testing, 12(1), 61-77.

Fidan, N. ve Erden, M. (1994). Eğitime giriş. Ankara: Meteksan Matbaacilık.

Hanushek, E. A., \& Rivkin, S. G. (2006). Teacher quality. Handbook of the Economics of Education, 2, 1051-1078.

Hsieh, H. \& Shannon, S. E. (2015). Three approaches to qualitative content analysis. Qualitative Health Research, 15(9), 1277 1288.

Küçükahmet, L. (1999). Öğretmenlik mesleğine giriş. (2. Basım). İstanbul: Alkım Yayınevi.
Lewis, L., Parsad, B., Carey, N., Bartfai, N., Farris, E., \& Smerdon, B. (1999). Teacher quality: A report on the preparation and qualifications. Education Statistics Quarterly, 1(1), 1-79.

MEB (2006). Öğretmenlik mesleği genel yeterlikleri. Ankara: Öğretmen Yetiştirme ve Eğitimi Genel Müdürlüğü

MEB (2007). Okul temelli mesleki gelişim okul yöneticisi ve öğretmenler için mesleki gelişim kılavuzu. Ankara: Öğretmen Yetiştirme ve Eğitimi Genel Müdürlügü.

MEB (2008). Öğretmen yeterlikleri. Öğretmenlik mesleği genel ve özel alan yeterlikleri. Ankara: Devlet Kitapları Müdürlüğü.

MEB (2017). Öğretmenlik mesleği genel yeterlikleri. Ankara: Öğretmen Yetiştirme ve Eğitimi Genel Müdürlüğü.

MEB, (2002). Öğretmen yeterlikleri. Öğretmen Yetiştirme ve Eğitimi Genel Müdürlüğü. Ankara: Millî Eğitim Basımevi.

Merriam, S. B. (2002). Introduction to qualitative research. Qualitative research in practice: Examples for discussion and analysis, 1(1), 1-17.

Merriam, S. B. (1998). Qualitative Research and Case Study Applications in Education. Revised and Expanded from" Case Study Research in Education.". Jossey-Bass Publishers, 350 Sansome St, San Francisco, CA 94104.

Merriam, S. B. (2013). Nitel araştırma: Desen ve uygulama için bir rehber. Çev. Ed. Sellahattin Turan). Ankara: Nobel Yayın Dağıtım.

Miles, M. B. \& Huberman, A.M. (1994). Qualitative data analysis: an expanded sourcebook. (2nd Edition). Calif: SAGE Publications.

Özdemir, S. ve Yalın, H. İ. (1999). Öğretmenlik mesleğine giriş. (2. Basım). Ankara: Nobel Yayın.

Özyürek, M. (2008). Nitelikli öğretmen yetiştirmede sorunlar ve çözümler: Özel eğitim örneği. Türk Eğitim Bilimleri Dergisi, 6(2), 189-226.

Peacock, A., \& Gates, S. (2000). Newly qualified primary teachers' perceptions of the role of text material in teaching science. Research in Science \& Technological Education, 18(2), 155171.

Seferoğlu, S. S. (2001). Sınıf öğretmenlerinin kendi mesleki gelişimleriyle ilgili görüşleri, beklentileri ve önerileri. Milli Eğitim Dergisi, Ocak-Şubat-Mart 2001, (149), 12-18.

Şeker, H., Deniz, S., \& Görgen, İ. (2005). Tezsiz yüksek lisans öğretmen adaylarının öğretmenlik yeterlikleri üzerine değerlendirmeleri. Kuram ve Uygulamada Eğitim Yönetimi, 42 (42), 237 253.

Taşkaya, S. M. (2012). Nitelikli bir öğretmende bulunması gereken özelliklerin öğretmen adaylarının görüşlerine göre incelenmesi. Erciyes Üniversitesi Sosyal Bilimler Enstitüsü Dergisi, 1(33), 283-298.

Thompson, S., \& Smith, D. L. (2005). Creating highly qualified teachers for urban schools. Professional Educator, 27, 73-88.

Uygur, M., \& Çakır, Ö. (2015). İngilizce öğretmenliği lisans öğrencilerinin öz-yeterlik inançlarının farklı değişkenlere göre incelenmesi. Journal of Qafqaz University, 3(1), 89-104.

Yıldırım, A. ve Şimşek, H. (2018). Sosyal bilimlerde nitel araştırma yöntemleri (11. Baskı). Ankara: Seçkin Yayıncılık.

Yıldırım, A., Ünal, A., \& Çelik, M. (2011). Öğretmen kavramına ilişkin öğretmen, yönetici ve müfettiş algılarının analizi. Uluslararası Insan Bilimleri Dergisi, 8(2), 92-109. 